\title{
Observations contributing to certain aspects of the mechanism of spontaneous reciprocating tachycardia
}

\author{
Altan Onat \\ From the Section of Cardiology, Department of Medicine, \\ Cerrahpasa Medical Faculty, University of Istanbul
}

In 7 patients, none of whom had the WPW syndrome, analysis of recurrent paroxysms of supraventricular tachycardia strongly favoured the existence of re-entry in the AV junction as the underlying mechanisms. Paroxysms were abortive in 4 patients and sustained in the remaining 3. The initiating factors were partial $A V$ block and/or premature beats or premature depolarization from re-entrant impulses.

The following phenomena were documented pertaining to reciprocating tachycardias. (I) $V$ ariation in configuration and in polarity in the same lead of retrograde $P$ waves from junctional impulses; (2) substantial variation in atrial echo intervals during initial and terminal cycles as well as in sustained reciprocation; (3) regular alternation in atrial echo intervals; (4) irregular ventricular response due to blockage and/or concealment of junctional impulses when sustained reciprocation was associated with partial $A V$ block; (5) continuous recurrence of tachycardia as a result of unidirectional block below the site for the juncture of dual AV pathways; (6) persistence for many days of circus re-entry in the AV junction.

It is pointed out that, in the diagnosis of reciprocating tachycardia, the criterion of a difference between the configuration of the $P$ wave which initiates the tachycardia and the $P$ waves recorded during the tachycardia is not obligatory.

Reciprocal beating, the most likely example of re-entry within the $A V$ junction, is a process due to temporal dispersion of refractoriness in the AV junction, in conjunction with areas of unidirectional block in some fibres. When the re-entry in the AV junction is bidirectional, the process may become self-perpetuating and be the source of paroxysms of supraventricular tachycardia (Pick and Langendorf, 1968) which is designated as reciprocating tachycardia (Kistin, 1965).

Reciprocating tachycardias may be initiated by atrial or ventricular premature systoles (Kistin, 1959, 1965; Gettes and Yoshonis, 1970) or they may be induced simply by partial AV block (Pick and Langendorf, 1950; Codina-Altes and de Beristain, 1950; Bix, I95I; Schamroth, I960; Burchell, I964; Massumi, Kistin, and Tawakkol, 1967). Various aspects concerning the mechanism of reentrant supraventricular tachycardias have been recently studied and analysed by use of

Received I4 July I97I. intracavitary atrial electrograms and/or His bundle recordings after premature electric stimulation of the heart (Durrer, Schuilenburg, and Wellens, 1969; Coumel et al., 1970; Bigger and Goldreyer, 1970; Castillo and Castellanos, 1970). It has been shown that supraventricular tachycardias may be abolished by an appropriately timed atrial (Hunt et al., 1968; Barold et al., 1969; Coumel et al., I970) or ventricular (Zeft and McGowan, I969; Coumel et al., I970) stimulation and that the site of re-entry lies within the AV junction (Goldreyer and Bigger, 1971).

The present paper is based on 7 cases of reentrant supraventricular tachycardia not having the WPW syndrome. In 4 of them there were very brief (abortive) paroxysms of reentrant tachycardia, while the other 3 had sustained reciprocation. The paroxysms occurred during sinus rhythm in 4 cases, in the course of AV junctional tachycardia in 2, and of atrial tachycardia in one patient. These observations may indicate some of the reasons for spontaneous initiating factors, activation 
wave of the atria, atrial echo intervals, ventricular response to re-entrant impulses, rate and course of the reciprocating mechanism. $=$

\section{Report of cases}

The salient clinical and electrocardiographic features of the 7 cases are summarized in the Table.

\section{Discussion}

Seven cases have been presented with recurrent episodes of supraventricular tachycardia, in the absence of the Wolff-Parkinson-White syndrome, which were due to a reciprocating mechanism in the AV junction. The diagnosis was consistent with previously proposed criteria, reviewed by Gettes and Yoshonis (I970), for reciprocating tachycardia of sinus or atrial origin. In this regard, it is worth pointing out that the criterion of a difference between the configuration of the $\mathrm{P}$ wave which initiates the tachycardia and the (superiorly directed) $P$ waves recorded during tachycardia, though theoretically valid, is not obligatory in all instances. Several factors may contribute to this apparent discrepancy: (a) retrograde atrial activation may produce upright $P$ waves in leads II, III, and aVF, as proved experi-

TABLE Clinical and electrocardiographic characteristics of cases with reciprocating tachycardia

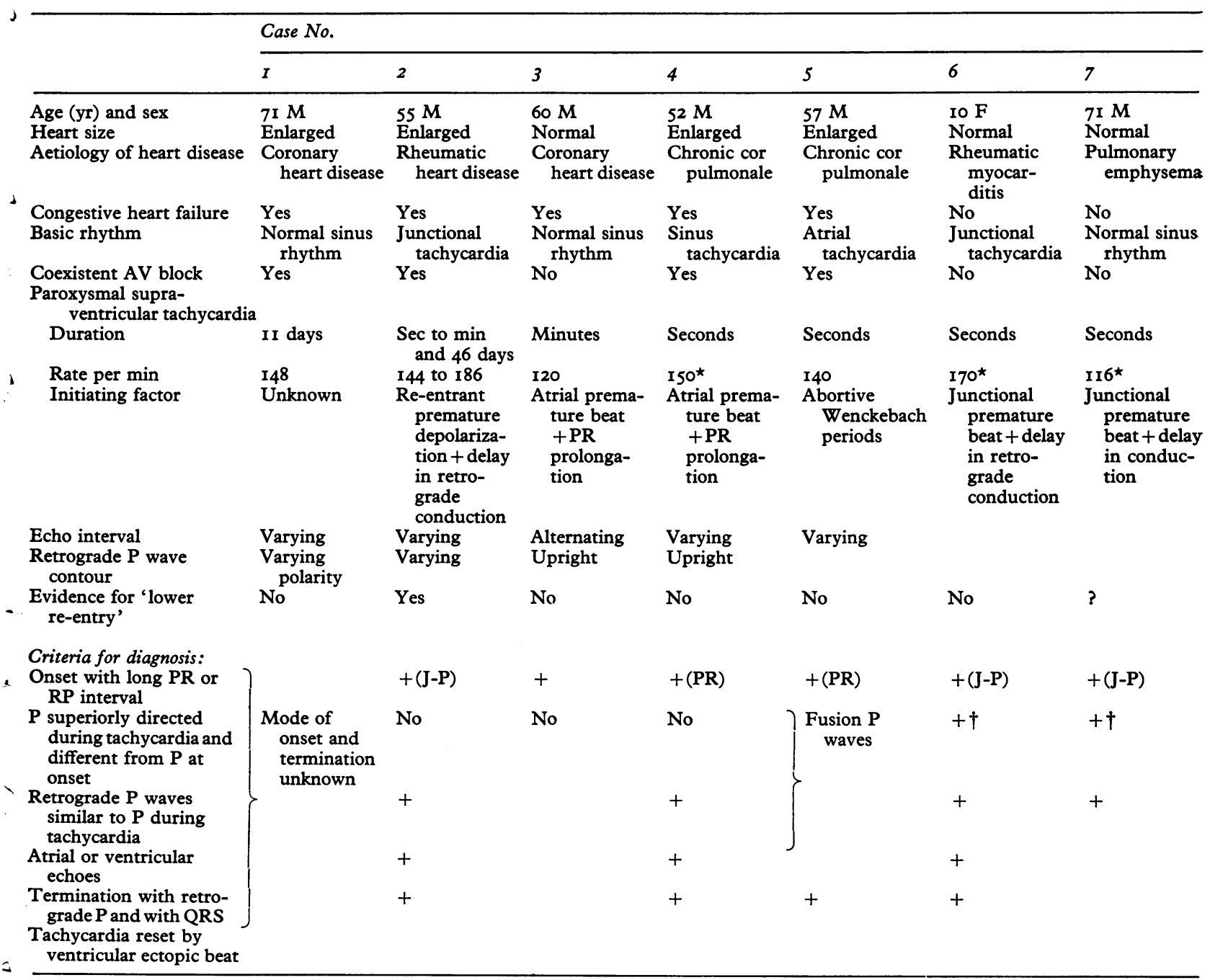

* Rates apply to abortive paroxysms of tachycardia.

$\uparrow$ Not different from $P$ at the onset, since the initiating impulse is junctional in origin.

$\mathrm{J}-\mathrm{P}$, Patients with reciprocation of junctional origin; $\mathrm{J}$ represents the assumed time at which the excitation front divides or the time of onset of junctional impulse. 


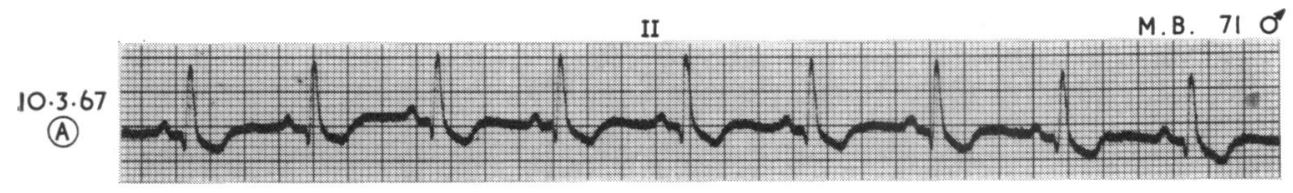

20.3.67

(B)

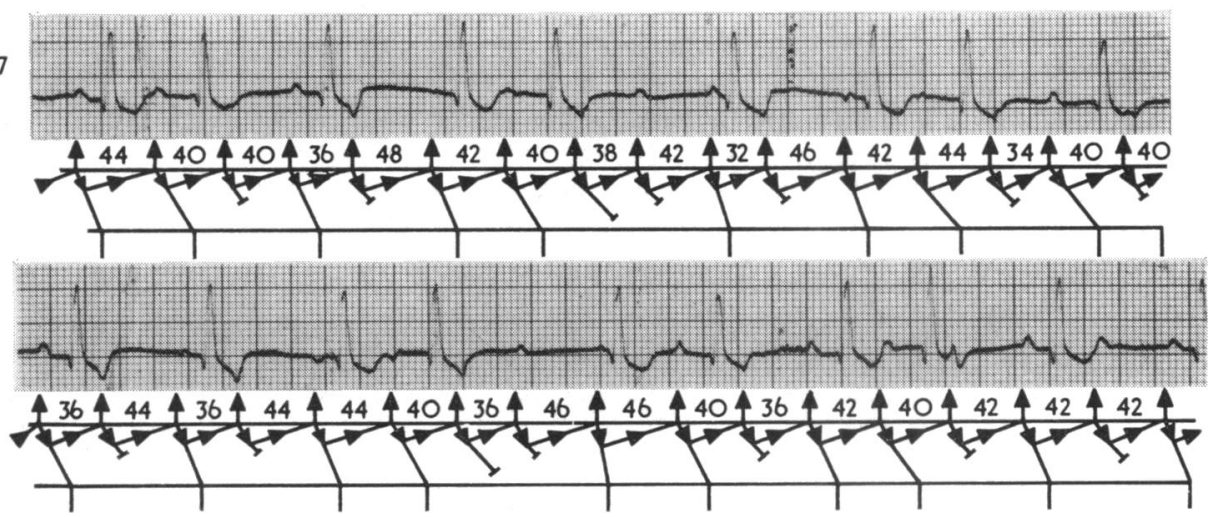

FIG. I Case I. (A) Normal sinus rhythm (rate 82 per min). (B) Reciprocating tachycardia (rate 148/min) disclosing distinct variation in the contour of the $P^{\prime}$ wave as well as in presumed re-entry cycle lengths.

mentally (Moore et al., 1967) and shown in man (Waldo et al., 1968, 1970) and as illustrated here in Cases $1,2,3$, and 4 ; consequently, $\mathbf{P}$ waves recorded during tachycardia need not have a superiorly directed vector; (b) the occurrence of atrial fusion beats between antegrade atrial impulses and atrial echoes if the discharge rate of the atrial pacemaker and the rate of the reciprocating tachycardia happen to be close to each other as occurred in Case 5; and (c) the presence of cases in which the $P$ wave initiating the tachycardia is of AV junctional origin, as applies to Cases 2 and 7.

The first 3 cases furthermore indicate that considerable variation in the contour and in the polarity of retrograde $\mathbf{P}$ waves may occur in the same lead.

In assessing the initiating factor of the reentry mechanism in patients already with an AV block, it is difficult to incriminate a single one of the two factors, namely premature depolarization of and conduction delay in the AV junction, since the latter varies with the prematurity of the impulse. Premature beats seemed the predominant factor in 4 patients, and premature depolarization from retrograde re-entrant impulses in a fifth patient. Four cases had coexistent AV block already during the basic rhythm. At the onset of the tachycardia, AV conduction in one or both directions was delayed in the remaining 3 patients.

Considerable variation in echo interval existed during the initial cycles and, to some extent, during the terminal cycles of the reentrant tachycardias. Shorter and longer cycles alternated before a stable supraventricular tachycardia cycle became established in Cases 2 and 3. These variations were more prominent in 4 patients with unsustained tachycardia. Variation in cycle length during the initial cycles of spontaneous re-entrant tachycardia was clearly documented by Bigger and Goldreyer (1970). A regular and true alternation in atrial echo intervals was noted during sustained reciprocation in Case 3. This is an undescribed feature consistent with reciprocal relation in re-entry cycles (Bigger and Goldreyer, 1970).

Cases I and 2 indicate that irregular ventricular responses may be elicited secondary to blockage and/or concealment of forward junctional impulses in a sustained reciprocation. Thus, a circus re-entry in the AV junction may occasionally be the basis of an apparent bigeminy.

Case 2 presented evidence for an area of unidirectional block below the site for the juncture of dual AV pathways. Two patterns of $\mathbf{P}$ wave spacing prevailed immediately preceding the reciprocating tachycardia (upper two strips of Fig. 2 and first strip of Fig. 3). This suggests that impulses giving rise to $\mathbf{P}_{2}$ (or blocked $\mathbf{P}_{2}^{\prime}$ ) and to $\mathbf{P}_{3}^{\prime}$ both originate from a re-entry in an area of unidirectional block further below in the AV junction. Reciprocating tachycardia did not result from a circus movement in the lower re-entry, 


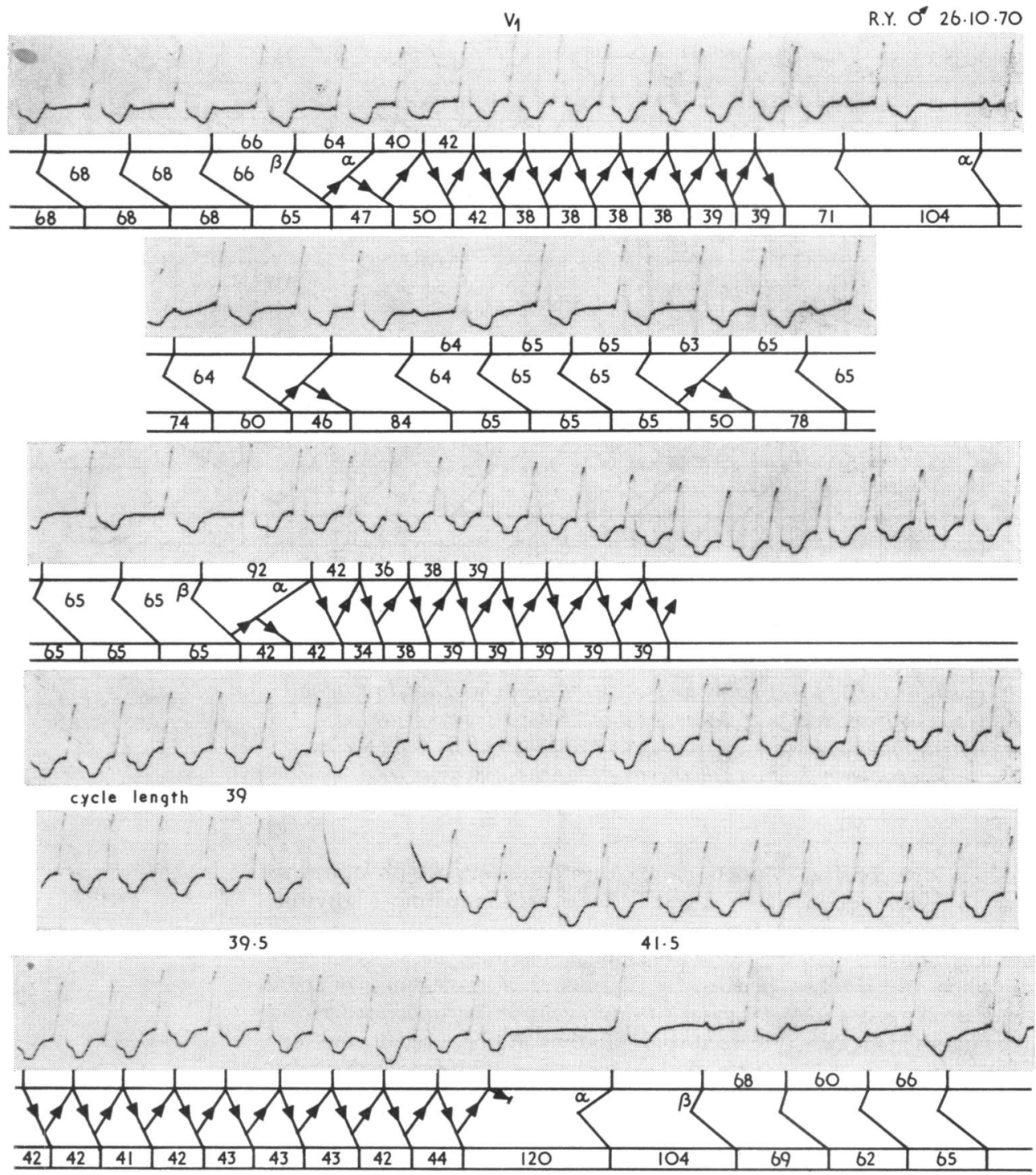

FIG. 2 Case 2. Paroxysms of reciprocating tachycardia in the course of an AV junctional tachycardia (lead VI, continuous strip). The beginning of the first strip shows an $A V$ junctional (or low atrial) rhythm at a rate of 88/min with forward partial $A V$ block. The fifth ventricular cycle shortens abruptly to $0.47 \mathrm{sec}$ which is interpreted as a re-entry in retrograde direction followed by one in forward pathways. The following bidirectional re-entry in the AV junction results in a reciprocating tachycardia for 9 cycles (rate $155 / \mathrm{min}$ ). Thereafter, the basic $A V$ junctional pacemaker takes over control. Of the 3 subsequent re-entries, the junctional impulse in the third strip sets off a new paroxysm of reciprocation. This time its mode of onset appears different. The following bidirectional re-entry lasts for 65 cycles. Its rate, initially $153 / \mathrm{min}$, slows gradually to $144 /$ min. Finally, the basic junctional tachycardia supervenes again. 

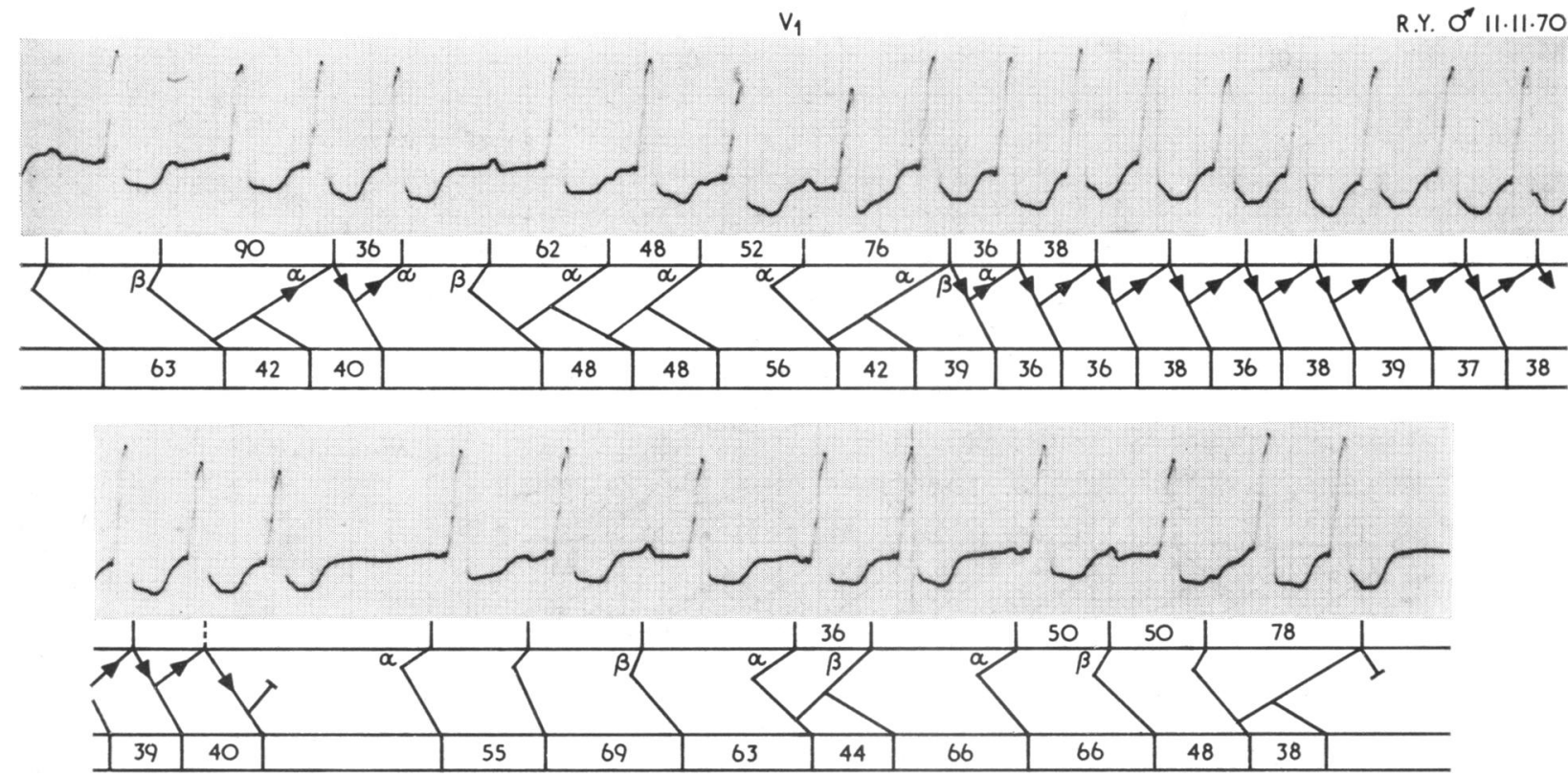

FIG. 3 Continuous strip, lead VI, of Case 2 (after administration of alprenolol). The second junctional impulse re-enters the area of unidirectional block and, in turn, the dual AV pathways for one cycle. The following junctional impulse produces 2 consecutive re-entries. The subsequent junctional impulse being early has to traverse the $\alpha$ pathway, re-enters the area of unidirectional block, and induces for 10 cycles a re-entrant tachycardia in the dual AV pathways (rate I60/min). The subsequent junctional impulses have a cycle length of approximately $0.62 \mathrm{sec}$ but the respective $P P^{\prime}$ or $R R$ intervals vary depending on whether the $\alpha$ or $\beta$ pathway is used.

however, but involved an upper area consistent with the concept of dual AV conduction pathways (Moe, Preston, and Burlington, 1956; Moe, Cohen, and Vick, 1963). This assumption was supported when two weeks later the patient developed a prolonged sustained tachycardia of somewhat higher rate associated with a 2: I AV conduction.

In our opinion, the moderate variance in the estimated re-entry time in the lower area of unidirectional block enhanced the frequent recurrence of the reciprocating tachycardia. Stated differently, the frequent re-entries in the lower area of the AV junction supplied the juncture of dual AV pathways in the upper area with retrograde impulses of variable prematurity, so that, in timing, many of them initiated a reciprocating tachycardia. This interpretation appears to explain the prominent and distinct clinical features in Case 2: the very frequent paroxysms of short duration, rapidly recurring within seconds or minutes of its spontaneous termination, and the presence of isolated or repetitive beats attributable to a re-entry process frequently seen between the paroxysms so that the basic junctional rhythm could often with difficulty be called the 'predominating' rhythm (Fig. 3).

Similar clinical features have been described by Coumel et al. (1970) in 4 of their 26 cases of supraventricular tachycardia due to reciprocal rhythm. As opposed to the features of classical paroxysmal supraventricular tachycardia, in these 4 patients classified in group A there were very frequent episodes of short duration; the paroxysm started with a normal PR interval (when the sinus cycle shortened below a certain value). Isolated atrial echo beats were frequently visible between the episodes, and a bout of tachycardia could be more readily induced by electrical stimulation. Gettes and Yoshonis (1970) reported 7 cases of rapidly recurring supraventricular tachycardia due to a reciprocation mechanism. In 2 of these cases the PR interval of the atrial echo was normal and tachycardia occurred when the RP interval was prolonged (Gettes and Yoshonis, 1970; Schamroth and Yoshonis, 1969). Evidence for reentry in an area of unidirectional block was not seen in these cases. 

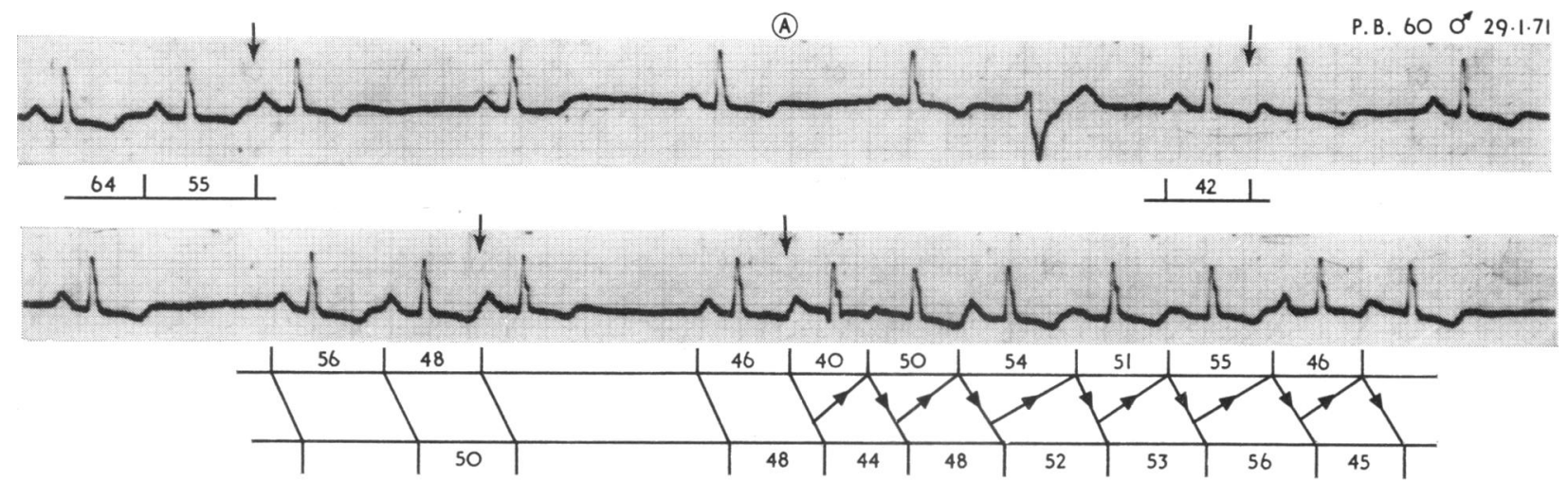

(B)
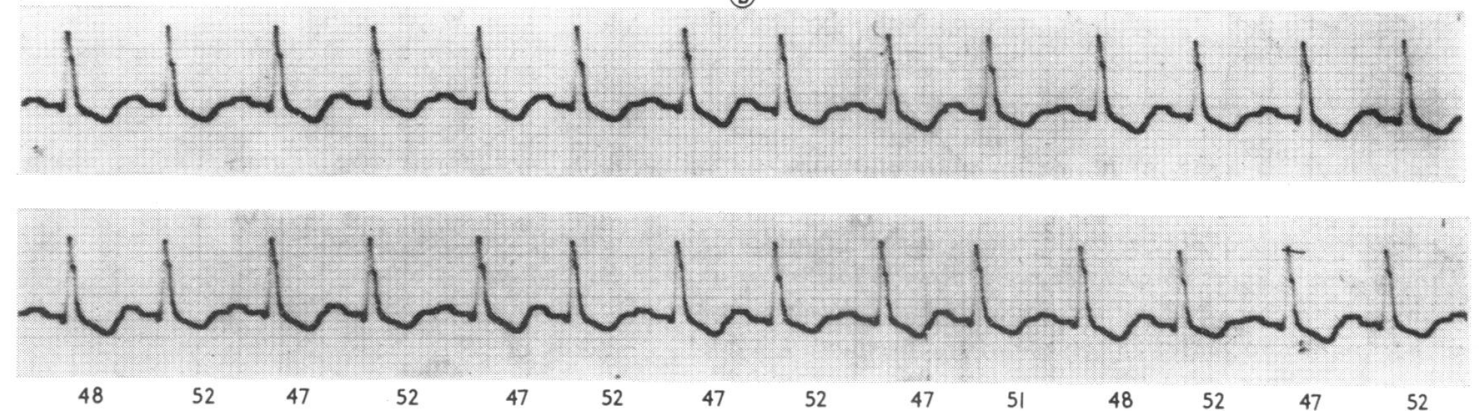

FIG. 4 Case 3. ( $A$ ) Lead II, continuous strip. During sinus depression (rate varying between 58 to $88 / \mathrm{min}$ ) 4 atrial premature beats appear $0.55,0.42,0.48$, and $0.46 \mathrm{sec}$, respectively, after the previous ventricular complexes. The last atrial premature beat initiates a supraventricular tachycardia for 6 cycles in which the duration of the atrial (as well as ventricular) cycles varies considerably. (B) Lead II, continuous strip. There is an atrial or junctional tachycardia (rate I20), exhibiting alternation not only of ventricular but also of atrial cycle lengths as seen by PP intervals alternating between 0.48 and $0.52 \mathrm{sec}$. The $P R$ interval is not significantly affected. The IP alternation probably represents an alternation in the AV conduction time of re-entrant impulses in dual $A V$ pathways. Conduction in the pathway with longer refractory period (say $\beta$ ) is significantly affected by the arrival time of impulses, which is dependent on the duration of the circus re-entry. When the re-entry circuit is traversed comparatively early (in $0.48 \mathrm{sec}$ ), conduction in the $\beta$ pathway would be delayed (by roughly $0.04 \mathrm{sec}$ ) which would induce prolonging to $0.52 \mathrm{sec}$ of the subsequent circuit time. This would, in turn, constitute a relatively late arrival of the re-entrant impulse at the $\beta$ pathway, thus permitting a faster conduction to effect completion of circus re-entry in $0.48 \mathrm{sec}$.

The gradual slight diminution in the rate of the tachycardia followed by a more indiscrete prolongation of the re-entrant cycle immediately before its spontaneous termination (Fig. 2) is conceivably explained by minor changes in the refractoriness of the AV con- ducting system consequent to alteration in sympathetic tone so that the re-entrant impulse entered the re-entrant circuit progressively earlier in its relative refractory period with resultant conduction delay until conduction ceased. 
II
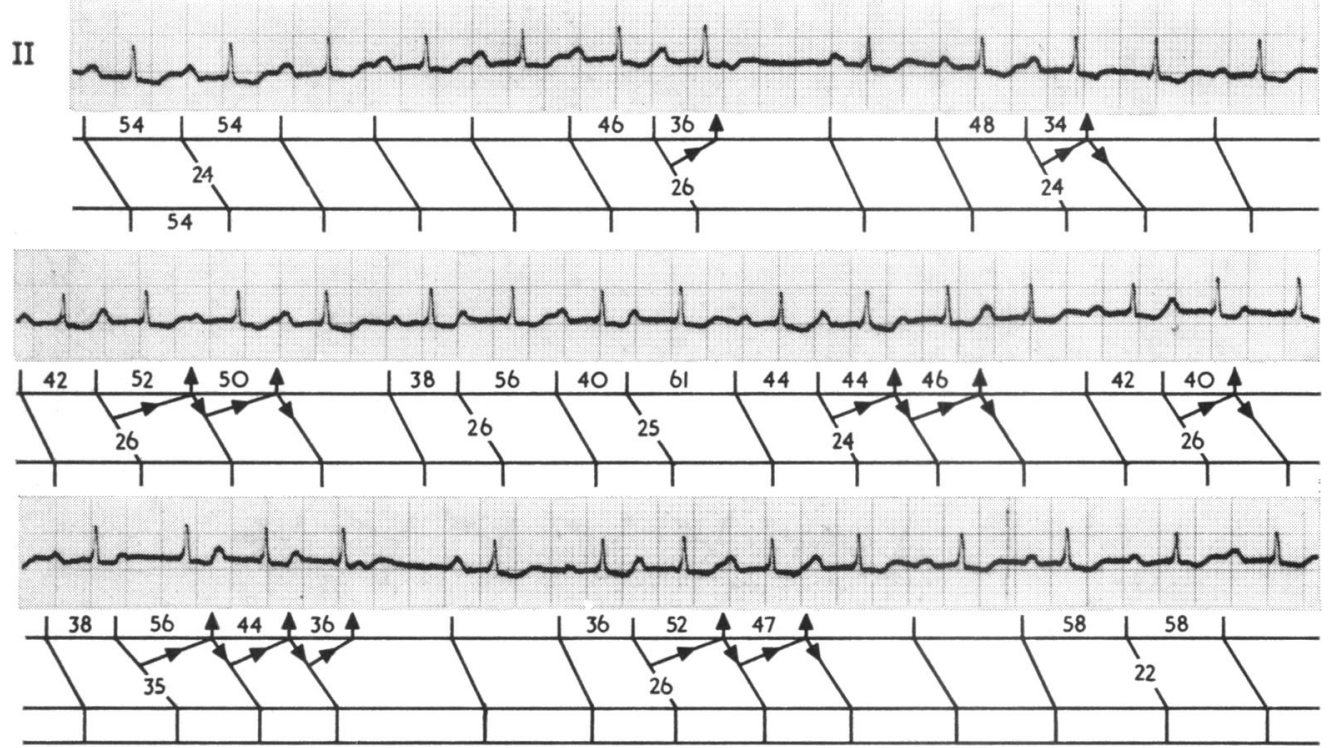

FIG. 5 Continuous strip, lead II of Case 4. In the course of a sinus tachycardia (IIO/min) and first-degree AV block, atrial ectopic beats occur at an RP interval of 0.36 to $0.48 \mathrm{sec}$. Except for the 2 in the middle of the second strip, all atrial premature beats cause atrial echoes, and most of them lead to short episodes of reciprocation lasting up to 3 cycles and ending with a $Q R S$ complex or a retrograde $P$ wave. Retrograde $P$ waves are upright as judged by the contour of those that are conducted after the end of the previous $T$ wave.

\section{References}

Barold, S. S., Linhart, J. W., Samet, P., and Lister, J. W. (1969). Supraventricular tachycardia initiated and terminated by a single electrical stimulus. American fournal of Cardiology, 24, 37.

Bigger, J. T., and Goldreyer, B. N. (1970). The mechanism of supraventricular tachycardia. Circulation, 42, 673.

Bix, H. H. (195I). Various mechanisms in reciprocal rhythm. American Heart fournal, 41, 448.

Burchell, H. B. (1964). Atrioventricular nodal (reciprocating) rhythm. Report of a case. American Heart fournal, 67, 391.

Castillo, C. A., and Castellanos, A., Jr. (1970). Mechanisms of retrograde conduction, ventricular echoes and reciprocating tachycardias as studied by $\mathrm{His}$ bundle recordings. Circulation, 42, Suppl. III, 143.

Codina-Altes, J., and de Beristain, C. P. (1950). Short paroxysms of tachycardia due to reciprocating rhythm. American Heart fournal, 39, 436.

Coumel, P., Motte, G., Gourgon, R., Fabiato, A., Slama, R., and Bouvrain, Y. (1970). Les tachycardies supraventriculaires par rythme réciproque en dehors du syndrome de Wolff-Parkinson-White. Archives des Maladies du Coeur et des Vaisseaux, 63, 35.

Durrer, D., Schuilenburg, R. M., and Wellens, H. J. (1969). The role of the atrio-ventricular junction in arrhythmias of the human heart. Proceedings. Koninklijke Nederlandse Akademie van Wetenschappen te Amsterdam, 72, 501.

Gettes, L. S., and Yoshonis, K. F. (1970). Rapidly recurring supraventricular tachycardia. A manifestation of reciprocating tachycardia and an indication for propranolol therapy. Circulation, 41, 689.
Goldreyer, B. N., and Bigger, J. T., Jr. (I97I). Site of re-entry in paroxysmal supraventricular tachycardia in man. Circulation, 43, 15.

Hunt, N. C., Cobb, F. R., Waxman, M. B., Zeft, H. J., Peter, R. H., and Morris, J. J. (1968). Conversion of supraventricular tachycardias with atrial stimulation: evidence for re-entry mechanism. Circulation, 38, 1060.

Kistin, A. D. (1959). Mechanisms determining reciprocal rhythm initiated by ventricular premature systoles. American fournal of Cardiology, 3, 365.

Kistin, A. D. (1965). Atrial reciprocal rhythm. Circulation, 32, 687.

Massumi, R. A., Kistin, A. D., and Tawakkol, A. A. (1967). Termination of reciprocating tachycardia by atrial stimulation. Circulation, 36, 637 .

Moe, G. K., Cohen, W., and Vick, R. L. (1963). Experimentally induced paroxysmal A-V nodal tachycardia in the dog. American Heart fournal, 65, 87.

Moe, G. K., Preston, J. B., and Burlington, H. (1956). Physiologic evidence for a dual A-V transmission system. Circulation Research, 4, 357.

Moore, E. N., Jomain, S. L., Stuckey, J. H., Buchanan, J. W., and Hoffman, B. F. (1967). Studies on ectopic atrial rhythms in dogs. American fournal of Cardiology, 19, 676.

Pick, A., and Langendorf, R. (1950). A case of reciprocal beating with evidence of repetitive and blocked re-entry of the cardiac impulse. American Heart fournal, 40, 13.

Pick, A., and Langendorf, R. (1968). Recent advances in the differential diagnosis of $\mathrm{A}-\mathrm{V}$ junctional arrhythmias. American Heart fournal, 76, 553. 

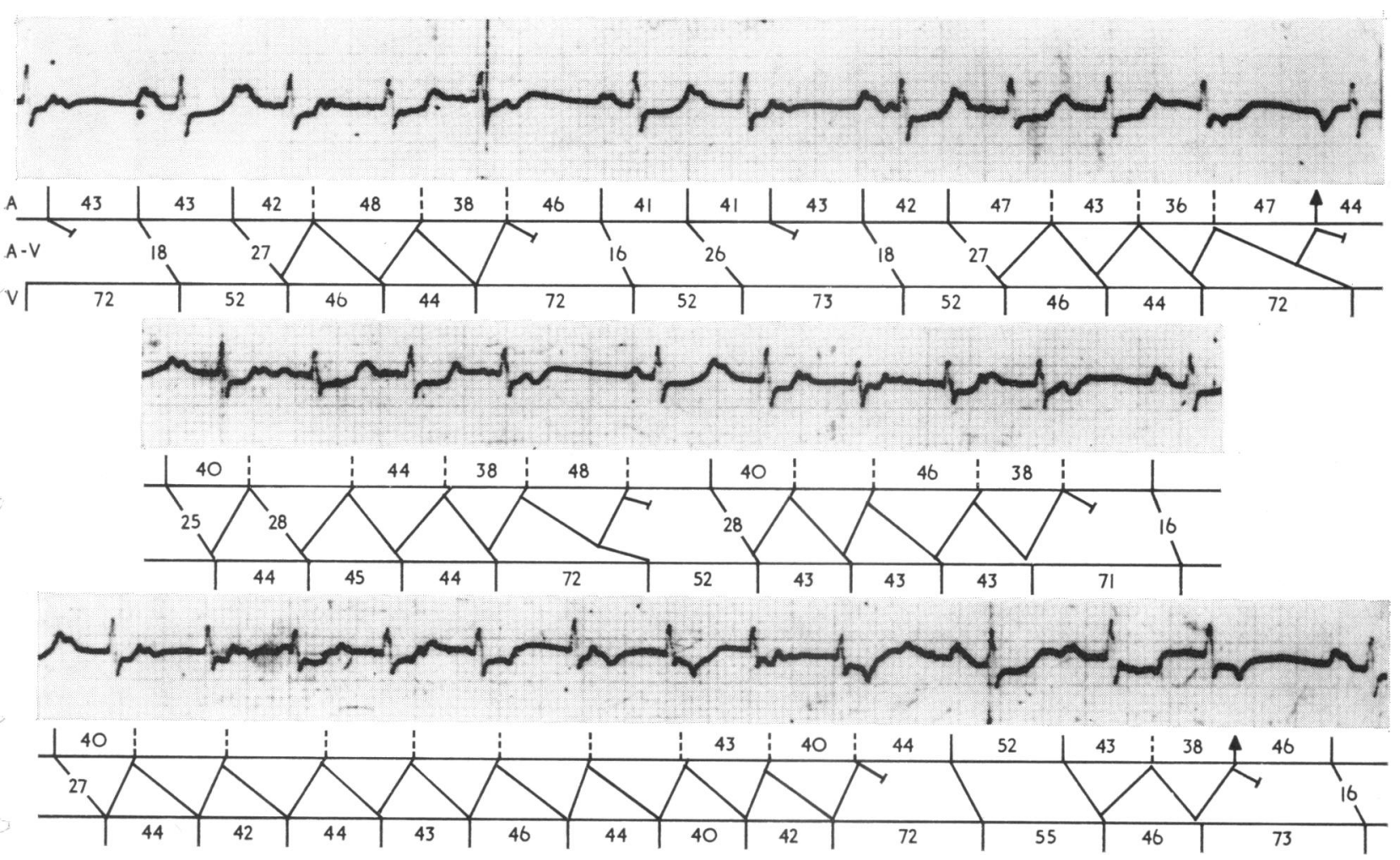

FIG. 6 Case 5. Reciprocation initiated by partial AV block in the course of an atrial

tachycardia. (Lead II, continuous strip.) There is an atrial tachycardia (rate 136 to 140 per min) associated with second-degree $A V$ block. The contour of the $P$ waves varies progressively for a few impulses. This indicates atrial fusion beats between impulses from the atrial pacemaker and retrograde impulses from the $A V$ junction. The $P$ wave eventually becomes retrograde in type, in which instance the atria are activated solely by the latter retrograde impulses. Re-entry occurs only during those atrial impulses having a delayed ( $0.25 \mathrm{sec}$ or more) AV conduction.

The resulting bouts of reciprocal rhythm are of short duration (from 3 to 9 successive beats).

FIG. 7 Repetitive nodal tachycardia with reciprocal beats in Case 6. The predominating rhythm is a repetitive AV junctional tachycardia (rate 109/min). Each group of junctional beats ends with a ventricular complex appearing prematurely, followed by a negative $P$ wave which is, in turn, followed by a long pause of $0.98 \mathrm{sec}$. The impulse giving rise to the retrograde $P$ wave re-enters in retrograde direction and occasionally elicits varyingly short episodes of reciprocation.

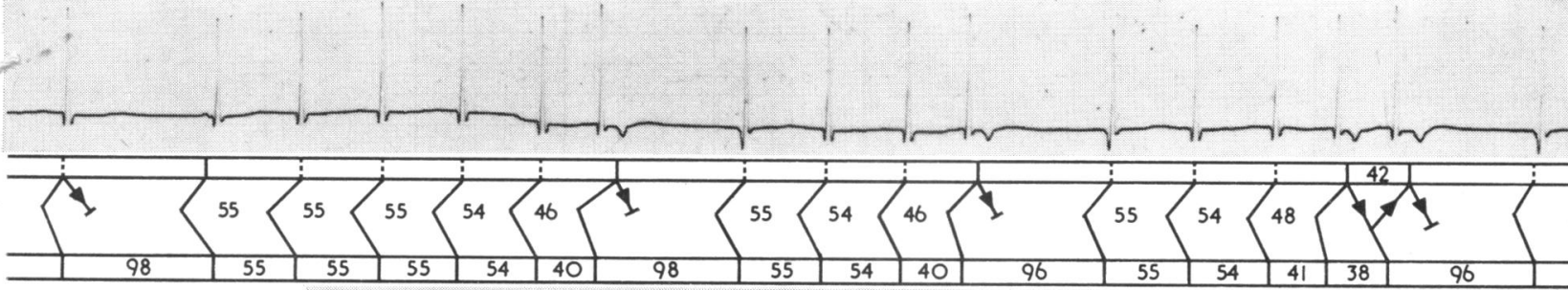

AVL

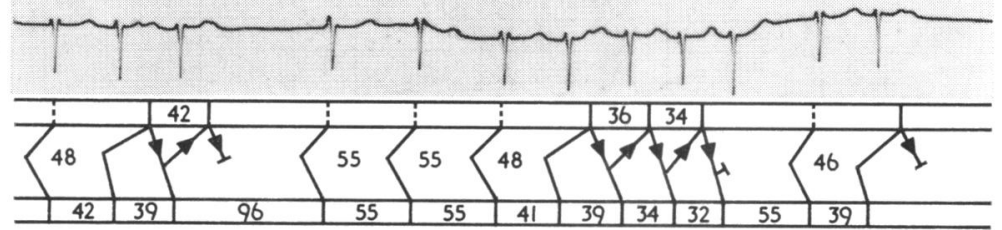


II
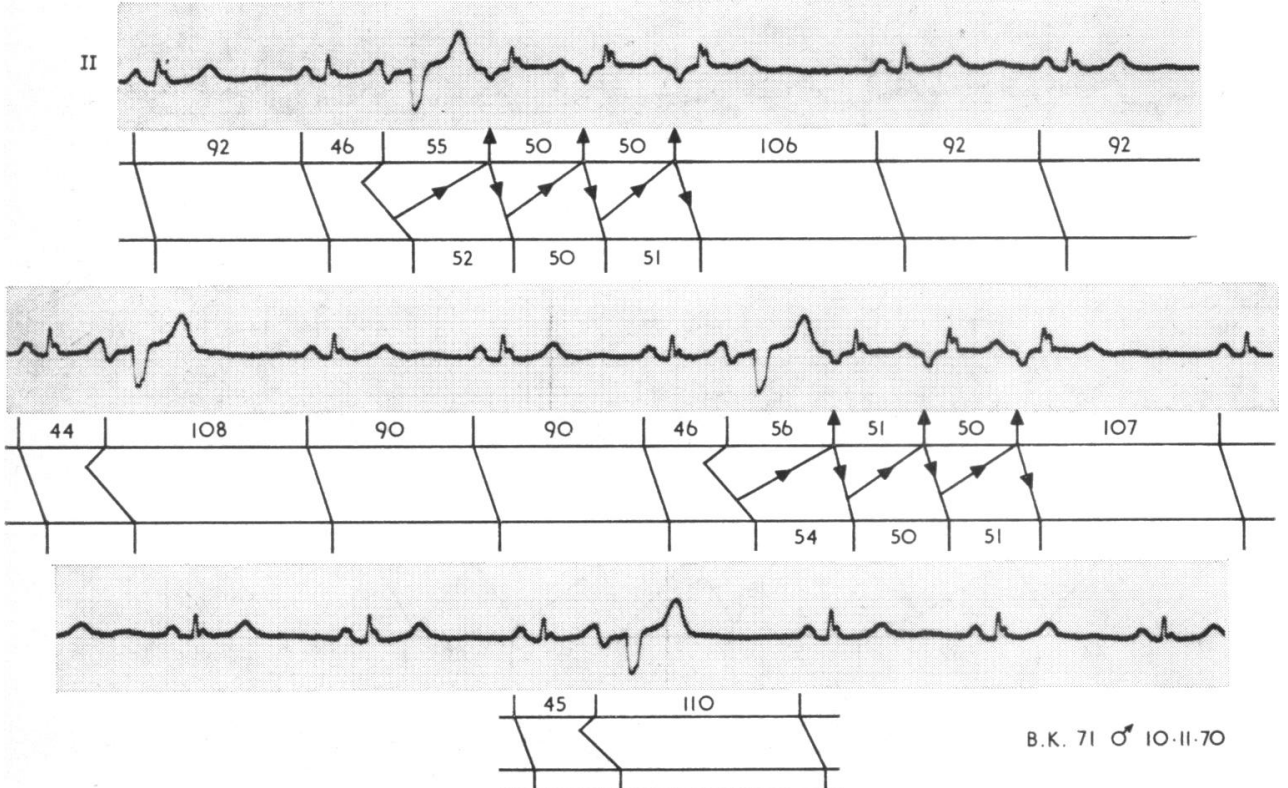

FIG. 8 Continuous strip, lead II, of Case 7. Short paroxysms of reciprocation initiated by junctional ectopic beats during normal sinus rhythm. The echo interval of the initial cycle is longer than the subsequent ones.

Schamroth, L. (1960). Reversed reciprocating paroxysmal tachycardia and its relationship to the WolffParkinson-White syndrome. American Heart fournal, 59, 506.

Schamroth, L., and Yoshonis, K. F. (1969). Mechanisms in reciprocal rhythm. American fournal of Cardiology, 24, 224.

Waldo, A. L., Vitikainen, K. J., Harris, P. D., Malm, J. R., and Hoffman, B. F. (I968). The mechanism of synchronization in isorhythmic $\mathrm{A}-\mathrm{V}$ dissociation: some observations on the morphology and polarity of the $\mathbf{P}$ wave during retrograde capture of the atria. Circulation, 38, 880.
Waldo, A. L., Vitikainen, K. J., Kaiser, G. A., Malm, J. R., and Hoffman, B. F. (I970). The P wave and P-R interval: effects of the site of origin of atrial depolarization. Circulation, 42, 653.

Zeft, H. J., and McGowan, R. L. (I969). Termination of paroxysmal junctional tachycardia by right

- ventricular stimulation. Circulation, 40, 919.

Requests for reprints to Professor Altan Onat, Section of Cardiology, Department of Medicine, Cerrahpaşa Medical Faculty, University of Istanbul, Turkey. 